\title{
Carteles y cartelistas
}

\author{
Sagrario aznar Almazan *
}

Aparte de revistas tan populares y de tirada tan elevada como el Blanco y Negro (1891-1936) de Torcuato Luca de Tena y La Esfera (1914-1930) de Francisco Verdugo Landi, o de colecciones de novelas cortas que podian ir desde El Cuento Semanal (1907-1912) y Los Contemporáneos (1909-1926) hasta La Novela Semanal (1921-1925) o La Novela Hoy (1922-1932), entre todos los mecanismos de difusión utilizados por los dibujantes e ilustradores gráficos madrileños del primer cuarto de siglo, el cartel publicitario, anunciador, será uno de los elementos más conocidos ayudado sin duda por su propia novedad y por su intrínseca función divulgadora. Colgado en la calle o reproducido en las revistas, era todo un género revolucionario cuyo empleo crecía a medida que aumentaba la necesidad de inducir rápidamente al consumo en una sociedad industrial cada día más poderosa. $Y$ es que la finalidad del cartel es básicamente funcional: se intenta vender un producto, hacerle publicidad, y, como señala Dorfles ', "sólo la publicidad actúa de manera totalmente interesada: si algo bueno, atrayente, nuevo, oportuno, es presentado por ella, no lo será por elevadas razones morales, o por motivos exquisitamente estéticos, sino por un fin en extremo trivial, y no obstante totalmente funcional, como es llevar al máximo de ventas posibles un determinado producto".

Por eso el lenguaje de los carteles es tan característico. Casi siempre se compone de dos niveles (el icónico y el literario) y nunca puede parecer oscuro o difícil de entender de manera que el diseñador tiene que lograr un contacto directo, reflejar sin ninguna duda el idioma más claro y popular, y conseguir que la función del cartel sea tan comunicati-

* Departamento de Historia del Arte. UNED.

' Dorfles, G., Naturaleza y Artificio, 1972, pág. 133. 
va como decorativa. Porque es, desde luego, un error, tratar de elaborar una historia de los carteles calcada sobre la historia del arte. El poster es absolutamente siempre obra de encargo y, como señala Melot ${ }^{2}$, "los publicistas saben muy bien qué es lo que determina el estilo de un cartel, es el gusto del público", por lo que más que una historia del arte paralela lo que realmente reflejan son las preferencias de la masa media. Sólo esto explica que la obra de artistas como Toulousse-Lautrec sea siempre una excepción y que la mayor parte de las veces no llegue a tener una aceptación popular hasta mucho más tarde, cuando el gusto de la mayor parte del público ya ha evolucionado. Su contraste con la producción, por ejemplo, de Jules Chéret (1836-1933) es evidente, sin ir más lejos, en los carteles que ambos hicieron para el Moulin Rouge en 1889 y 1891 respectivamente. En ellos se pasaba de un mundo amable que todavía bebía sin remordimientos en las fuentes del pasado, como señala Barnicoat ${ }^{3}$, al escenario del mundo moderno, porque Lautrec ya sabe eliminar los elementos tradicionales de la obra de Chéret exagerando, al mismo tiempo, ciertos aspectos expresivos que sin duda estaban latentes en ella. El resultado era muy simple: para la mayor parte del público los carteles de Lautrec eran "feos" y, con sus ásperas caricaturas y rigidas figuras, dejaban un sabor de inquietud, mientras que la atractiva y colorista obra de Chéret conseguía exactamente los resultados que el público buscaba.

Sim embargo, entre Chéret y Lautrec habían dejado un camino abierto. A partir de entonces, los carteles gozaron de un meteórico ascenso en popularidad, desarrollando un lenguaje propio que alcanzará uno de sus puntos culminantes con la llegada a París, en 1890, de Alphonse Mucha (Bohemia, 1860 - Praga, 1930), que con su estilo preciosista, "bizantino", tan diferente a la forma libre de Lautrec, pero igualmente trabajado y cuidado en las composiciones, hizo unos carteles que, desde “Gismonda" en 1894, están relacionados con la actriz Sarah Bernhard, aparecen adscritos a la moda internacional del Art Nouveau y, por lo tanto, gozan de una fuerte y segura aceptación general. En 1905 y en París publica, con sus Lectures on $\mathrm{Art}^{4}$, un intento de explicar en palabras las técnicas compositivas y las formas de su obra gráfica. Para él, la belleza de una línea está en relación directa con la fatiga de los músculos del ojo que la mira y, consecuentemente, cuanto más larga sea la línea, más desagradable será la fatiga, porque se debe siempre crear un

${ }^{2}$ Melot, L'Illustration: histoire d'un art, 1984, pág. 85.

${ }^{3}$ Barnicoat, Los carteles, su historia y su lenguaje, 1976, págs. 24-25.

4 Mucha, A., Lectures on Art. Londres, Adademy Editions, 1975. Primera edición de hacia 1905. 
punto de descanso en el camino. Para ello, las proporciones más acertadas, según Mucha, serán siempre de II a III porque es la más típica en la naturaleza y a la que el ojo está más acostumbrado. Por ejemplo, en su cartel anunciador "Bieres de la Meuse" la diagonal que forma el cuerpo de la muchacha puede dividirse en cinco partes de las cuales dos pertenecen a la cabeza y tres al resto del cuerpo. Además, la proporción ya conseguida se ve completada porque el radio en que se inscribe todo el conjunto de la cabeza, incluidos parte de los adornos, es también de dos módulos en una buena muestra de lo que Mucha llama "la relación armoniosa de las longitudes".

Pero además tiene que existir otro tipo de armonia, la armonia de los tres puntos, también en relación con la proporción de II a III. El mayor punto de interés debe estar determinado por esta ley; el segundo punto nunca debe ser colocado horizontalmente junto al primero o verticalmente encima o debajo del primero porque las líneas verticales y horizontales, nos dice el autor, no producen al espectador ningún placer especial ya que la horizontal es la simple repetición de la línea de nuestros ojos y la vertical está ligada a la condición de nuestro cuerpo; y el tercer punto, en fin, se colocará a una distancia que mantenga la misma proporción respecto al primero.

En el dibujo de 1893 que representa a una muchacha con túnica sentada en un círculo con una rosa en la mano, Mucha utiliza en una vertical que no está en lo que debiera ser el eje central matemático de la composición, dos módulos desde la cabeza hasta el pecho y tres desde el pecho hasta el remolino de ropa que se forma alrededor del pie, mientras que el radio de toda la zona de la cabeza tiene una longitud de dos módulos. El primer punto de interés está en los ojos de la muchacha, justo en la mitad del primero de los módulos que da la longitud de la cabeza. El segundo hay que buscarlo en la diagonal con la rosa hacia la que dirige la mirada, a tres módulos de distancia del primero, y el tercero y último en el pie, también a tres módulos de la flor, con lo que el triángulo compositivo queda cerrado.

La aplicación del arte a la decoración; los elementos de la ornamentación en los que subraya la importancia de enfatizar las líneas características esenciales y de no destruir el carácter plano de las figuras; el estilo y la composición; la armonía de la línea en el esquema general del diseño y la utilización del color, son algunos de los temas que Mucha aborda en su libro antes de llegar a otro de los puntos más importantes: la armonia de las masas en la composición. Para él, la armonia de una estructura compositiva depende de la simetría y del equilibrio de las masas. Cuando la distancia de dos puntos respecto a uno central es la 
misma, la propia simetria da equilibrio al diseño, pero cuando una de las dos distancias es más corta debe aumentarse la masa por ese lado para compensar la asimetría. En el ejemplo del cartel «Bieres de la Meuse» la diagonal que ocupa el cuerpo humano tiene dos distancias no iguales. La cabeza ocupa lógicamente menos espacio longitudinal que el resto del cuerpo $y$, por lo tanto, según esta teoría de la distribución de las masas, irá mucho más recargada de ornamentación para compensar y mantener el equilibrio.

Las teorías de Mucha dieron como resultado un grafismo muy cuidado, sofisticado y decadente, si se quiere, pero, desde luego, con una acusada influencia en la etapa más internacional del Art Nouveau como veremos más adelante en cartelistas que como Eulogio Varela y Sartorio trabajan en la primera etapa de los Bailes de Máscaras celebrados por el Círculo de Bellas Artes.

Pero en las primeras décadas del siglo $x x$ el gusto del público evolucionó con rapidez. La sed de "modernidad" de la burguesía se traduce ahora en las formas más simples del Art Deco, un estilo mucho más apto para el esquematismo de los carteles. Desde el "Frou-Frou" de Leonnetto Cappiello en 1899 , formado ya por una imagen instantánea fácilmente recordable, hasta la "Revue Negre" de Paul Colin en 1925, que anunciaba la primera actuación de Josephine Baker en Paris, se desarrolló un lenguaje del cartel bastante menos sofisticado, más simple y directo, en resumen, más moderno. Porque de todas las artes gráficas del período Deco, los carteles fueron una de las más afectadas por los movimientos de vanguardia. $Y$ aunque muchos diseñadores simplemente usaron el geometrismo y las nuevas técnicas para dar a sus carteles un aspecto superficial de modernidad, otros, más coherentes, como Cassandre (1901-1968), supieron utilizar los principios teóricos del Cubismo, el Futurismo o el Constructivismo en trabajos que empezaban ya a ser revolucionarios.

En España, el primer cartel que se puede considerar como tal es el de "Los gordos y los flacos" hecho por Francisco Ortego Vereda, un dibujante de El Semanario Pintoresco y de El Museo Universal, hacia 1870. Patrocinado por la firma Chocolates Matías López se trata de un cartel de encargo que representa, en un simple friso con la información escrita en la parte alta, a tres parejas diferentes tomando chocolate (fig. 1).

Sin embargo, lo normal en España no era tanto que los carteles se hicieran por encargo directo como que surgieran de los diferentes concursos convocados por las casas o industrias que querían anunciar sus productos. En marzo de 1898, Vicente Bosch, un industrial licorero de 


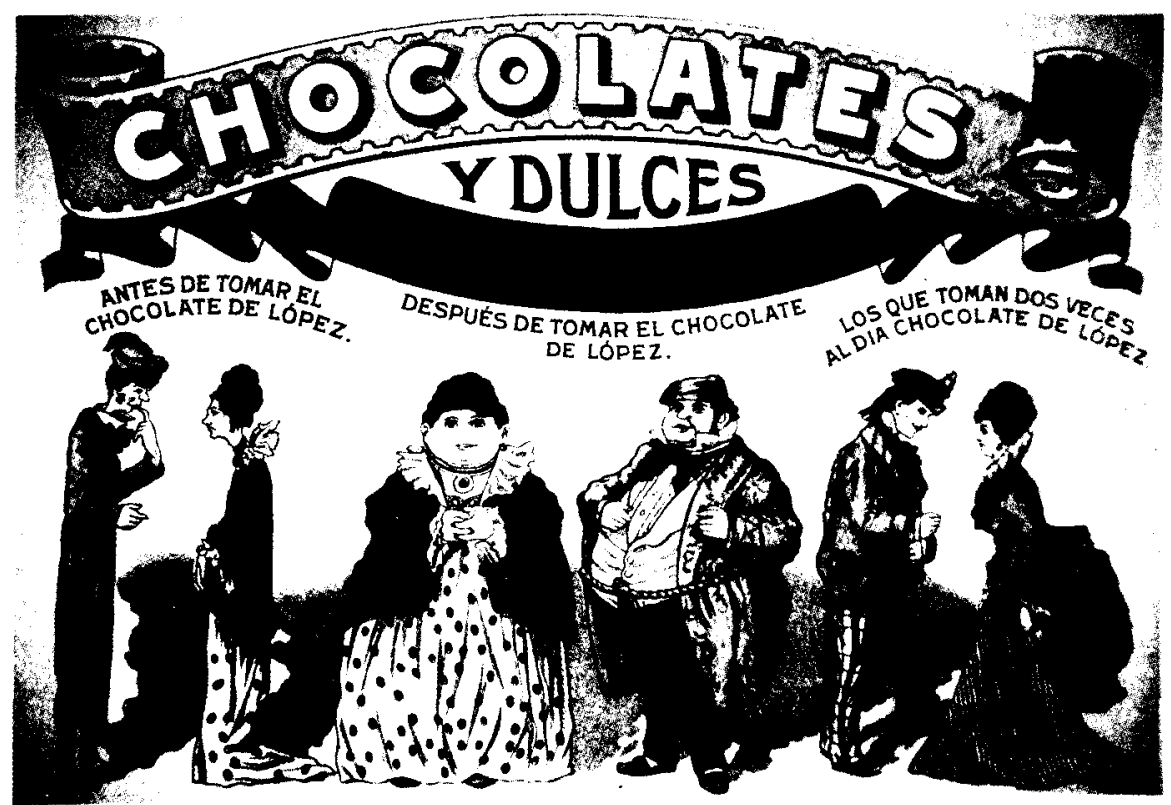

Fig. 1. Ortego Vereda, "Los gordos y los flacos", 1870

Barcelona, organiza el primer certámen para anunciar su "Anís del Mono». De los 167 carteles presentados, que se expusieron en la Sala Parés de Barcelona, la mayoría eran de artistas catalanes y muchos de ellos, incluido el que ganó el primer premio de Ramón Casas, están bastante influidos por el Nouveau internacional. Y la misma corriente estética se impone en el concurso que, en el mismo año, convocó Manuel Raventós, en Madrid, para anunciar el espumoso Codorniu y en el que el primer premio fue para Julio Tubilla, el segundo para el habitual Ramón Casas y el tercero para el ilustrador Francisco Cidón (figs. 2 y 3 )

Después de una corta serie de concursos sucesivos ${ }^{5}$, será la Perfumería Gal, que tenía fábrica en Madrid, la que empezará realmente a difundir el Art Deco en sus carteles a partir del concurso de 1916. Convocado en Barcelona con el fin de asentar un mercado catalán, la exposición de las 470 obras que fueron admitidas se celebró en los salones

${ }^{5}$ En 1902 el del Ayuntamiento de Madrid para anunciar las fiestas de mayo y en el que Fernando Alberti ganó un tercer premio por el titulado "Cincel del Trabajo"; en marzo de 1907 el de la Unión Alcoholera para anunciar alcohol desnaturalizado; y on 1914 el de la casa Amatller de chocolates que ganó Rafael de Penagos. 
del Círculo Artístico barcelonés, y los permios se distribuyeron entre los tres dibujantes más representativos del nuevo estilo en Madrid: Penagos, Ribas y Bartolozzi.

Salvador Bartolozzi, hijo del escultor italiano Lucas Bartolozzi, que se habia instalado en España a finales del siglo pasado, se quedó en Madrid, tras una breve estancia en París de 1901 a 1906, como uno de los cartelistas más cotizados. Amigo de Ramón Gómez de la Serna fue uno de esos asiduos a la tertulia del café Pombo que aparecen en el lienzo de Solana, y desde 1917 empezó a dirigir artísticamente la editorial de Saturnino Calleja, en la que publicó su famosa colección de "Pinocho". Como dibujante participó en dos Exposiciones Universales de París, la de 1925, en la que obtuvo un premio por sus carteles, y la del Pabellón de la República Española en 1937 con su hija Francisca Bartolozzi (Pitti). A su lado, el gallego Federico Ribas es probablemente el más elegante y fino dibujante de su generación. Instalado en Madrid desde 1916, tras una estancia en Buenos Aires en 1907 y un viaje a París en 1912, consigue pronto un buen nombre como el dibujante que, sin olvidar la lección de Beardsley, se vuelca hacia el tipo contemporáneo de mujeres modernas, arquetipos de un modelo envidiable que estaba haciendo furor en la época y que todas querian alcanzar.

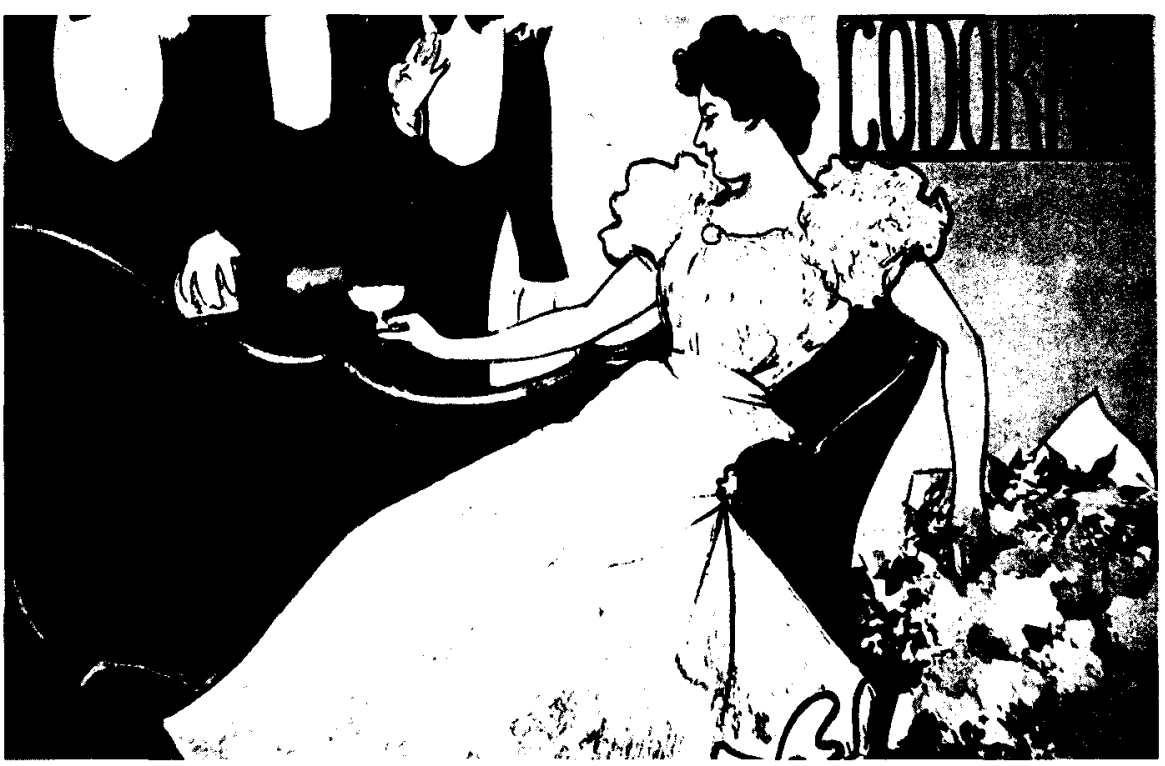

Fig. 2 Casas, Ramón. Cartel para Codorniu, 1898. 


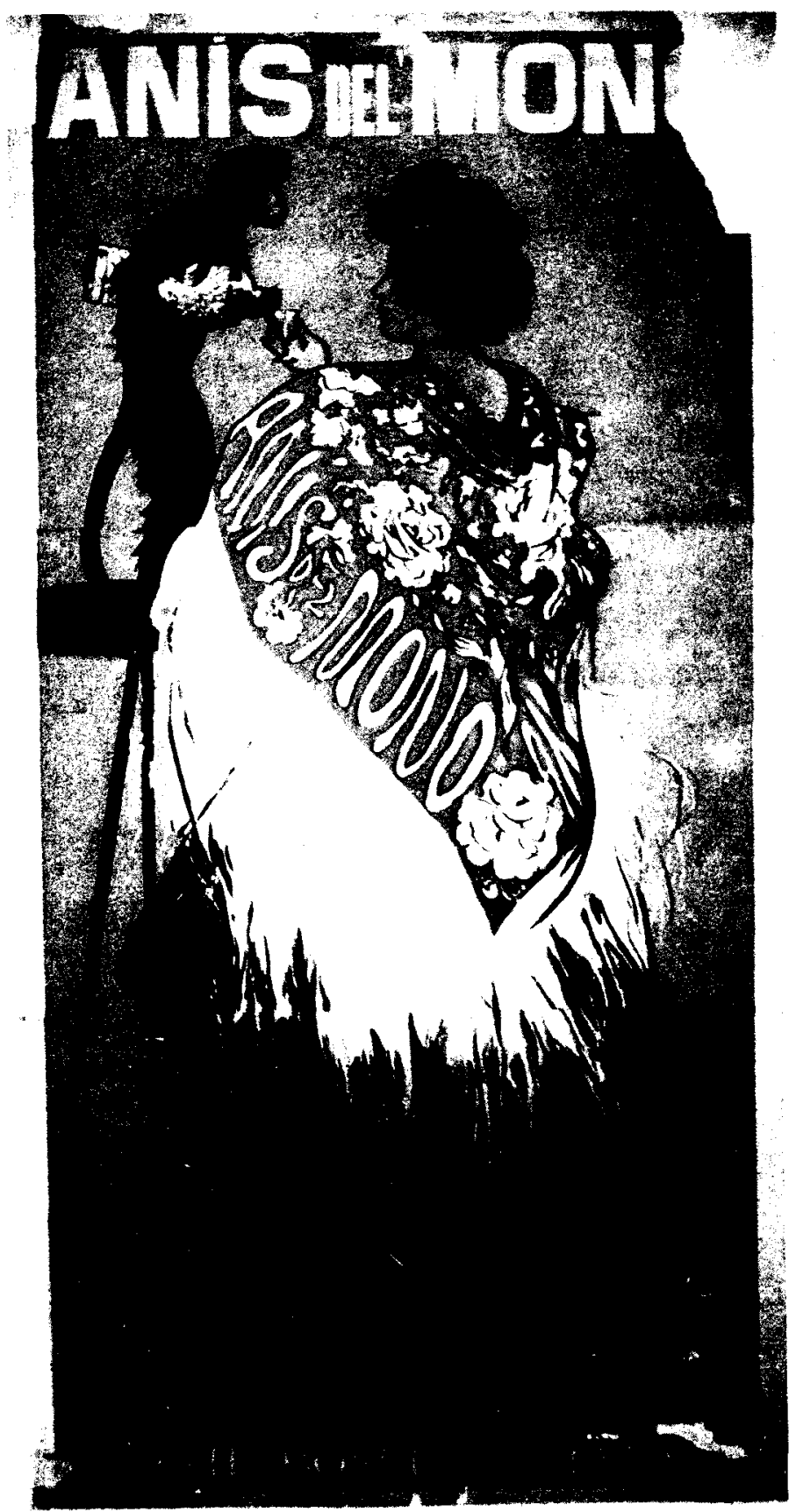

Fig. 3 Casas, Ramon, Cartel para Anis del Mono, 1898. 
Pero será Rafael de Penagos y Zalabardo, sin duda, el que merezca un punto y aparte porque en él se condensan todas las características del estilo que irán desarrollando todos los demás cartelistas. Madrileño, había estudiado en la Escuela Superior de Artes e Industrias y, desde 1904, en la Escuela de Bellas Artes de San Fernando con Emilio Sala y Muñoz Degrain como profesores. En 1913 es pensionado en París y en 1915 se instala definitivamente en Madrid donde empieza a trabajar, ade-

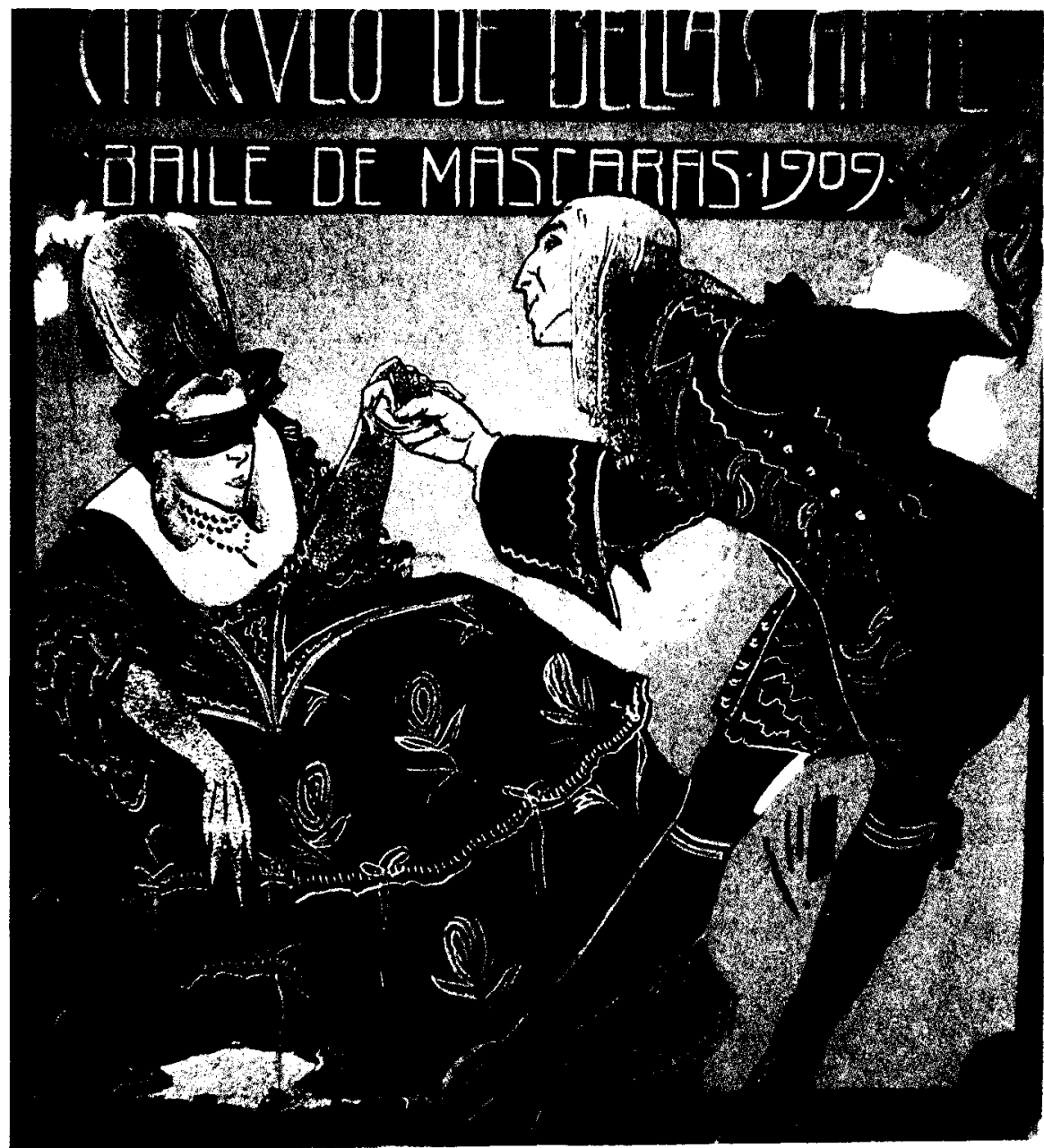

Fig. 4 Penagos, Rafael de "Watteau", Circulo de Bellas Artes de Madrid, 1909. 
más de en revistas y en colecciones de novelas cortas, para la editorial Calleja y donde también gana muchos premios en los diferentes concursos de carteles, llegando incluso a oscurecer la fama de sus compañeros (fig. 4, 5, 6).

De los tres, Federico Ribas pasó a ser director artístico de Gal, mientras que Penagos y Bartolozzi se quedaron como colaboradores libres

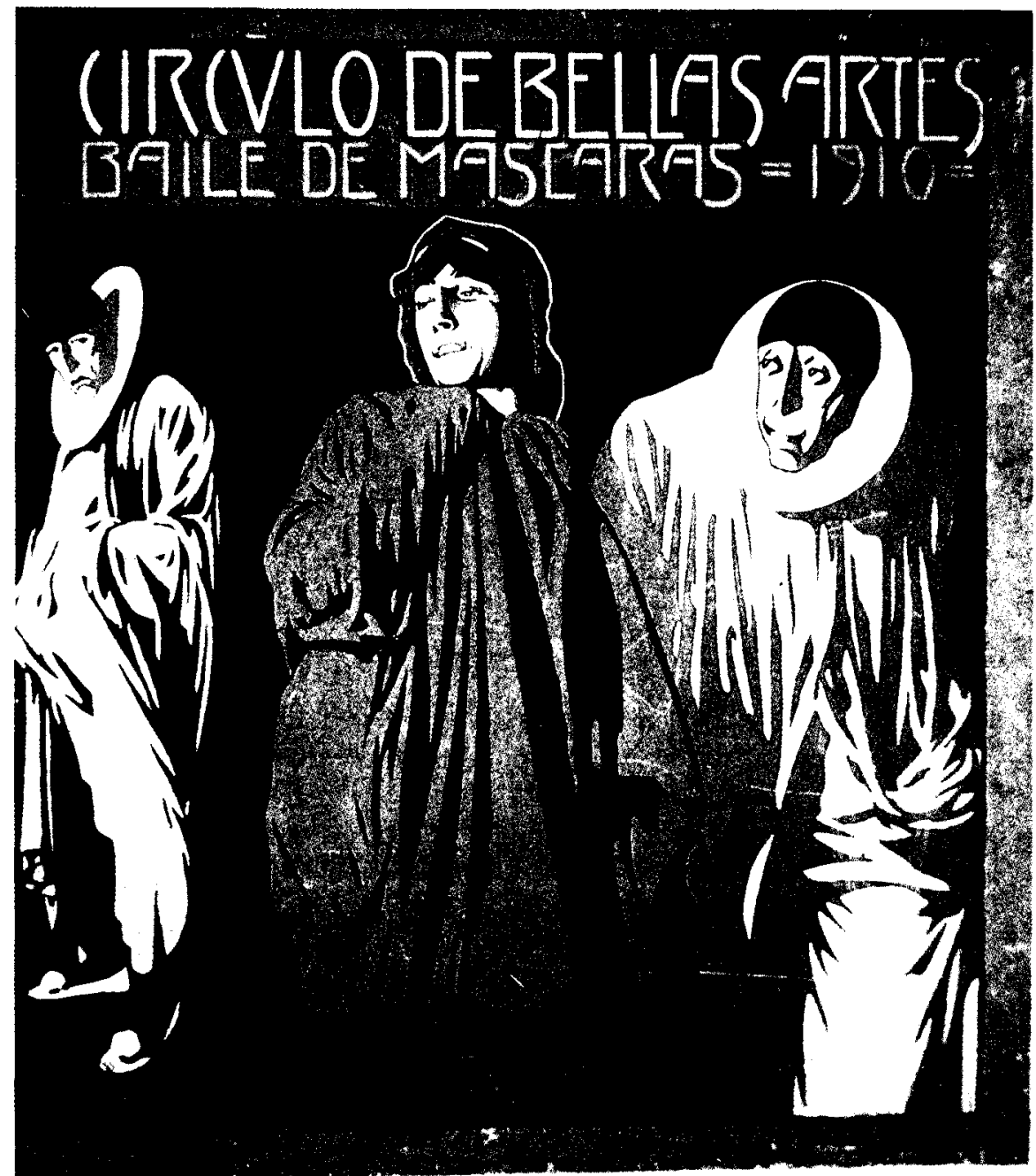

Fig. 5 Penagos, Rafael de "Trio serenata", Circulo de Bellas Artes de Madrid, 1910. 


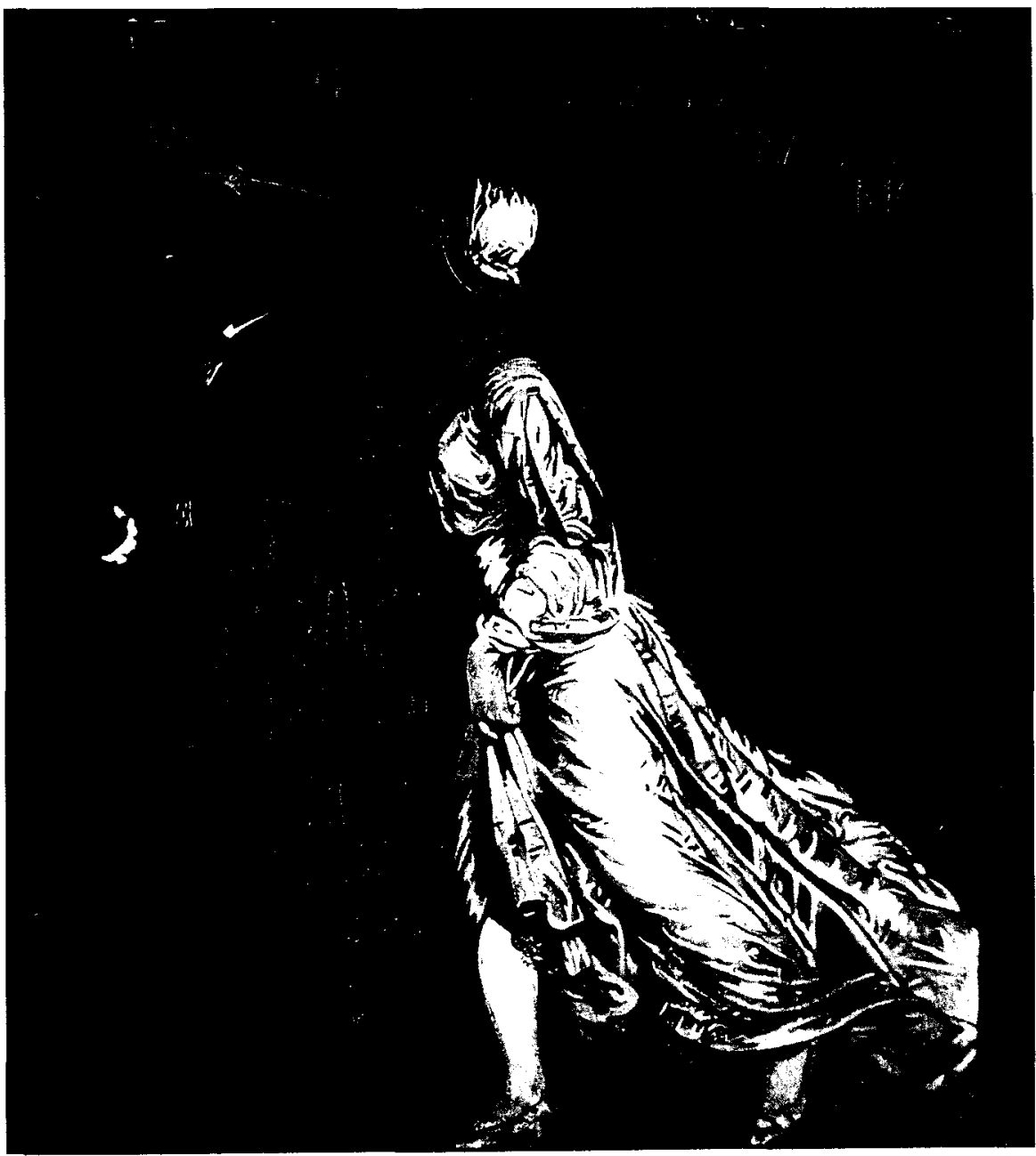

Fig. 6 Penagos, Rafael de “Firenze”, Circulo de Bellas Artes de Madrid, 1911.

del Departamento de Publicidad de la Perfumería Floralia. El resultado fue que de todos los anuncios de la casa que aparecian en las revistas habituales, como carteles reproducidos o como viñetas anunciadoras que desde finales del siglo pasado habian aumentado escandalosamente su volumen, Gal se caracterizó por el fino estilo de Ribas y Floralia por la variedad de sus colaboradores que incluia nombres, aparte de los mencionados, como Echea, Moya del Pino o Enrique Varela de Seijas. 
$Y$ es que la mayor parte de los carteles españoles son claramente publicitarios. Muy pocos de ellos, con la excepción quizás del que Fernando Alberti hizo para celebrar la coronación de Alfonso XII en 1902 o del de José García Ramos para conmemorar la Semana Santa y la Feria de Sevilla en 1912, son conmemorativos o artísticos, es decir, realizados por los dibujantes para eventos relacionados con su arte como el de Rafael de Penagos en 1915 para la Exposición Nacional de Bellas Artes o los sucesivos anunciadores de los Salones de Humoristas. Por eso, los convocados por el Círculo de Bellas Artes para anunciar su Baile de Máscaras son una excepción: conmemoran y anuncian una fiesta popular al mismo tiempo que se convierten en un auténtico certamen artístico anual. El Círculo de Bellas Artes se creó en 1880 gracias a la iniciativa de un grupo de artistas encabezados por el pintor valenciano Plácido Francés. Primero tuvo su sede en la calle Barquillo de Madrid para luego trasladarla a la calle Libertad y, más tarde, a la de Alcalá. En 1914 se fueron al local que había ocupado el Casino de Madrid, el edificio de la Equitativa, y en 1926, el arquitecto Antonio Palacios ya hace su propio edificio que se conserva hasta hoy en la misma calle Alcalá (figs. 7 y 8).

El primer Baile de Carnaval del Círculo se celebró en 10 de febrero de 1891 en el Teatro de la Comedia y la fiesta, tradicional en el Madrid de entonces, ya no tuvo interrupción hasta la guerra civil española. En un abanico de tiempo tan amplio, los carteles anunciadores que surgieron para dar a conocer estos bailes pasaron por todo tipo de estilos y modas. Al principio, simplemente se encargaban a artistas de lengüaje tradicional como Cecilio Plá en 1892 o Juan Francés en 1902, pero desde 1903 el acontecimiento se convierte en un concurso de carteles que se celebrará todos los años. $Y$ al margen de algún cartel Nouveau, importante por excepcional, como el "Arte, Juventud y Locura" del ilustrador del Blanco y Negro, Eulogio Varela y Sartorio, uno de los más interesantes representantes de un Modernismo tipo Alphonse Mucha en Madrid, el auténtico estilo que difundieron en su epoca de consolidación fue el Art Deco. (fig. 9) Desde 1910 aproximadamente, Penagos, Ribas y Bartolozzi, con algún otro de vez en cuando, se rifan los premios ${ }^{6}$, con un único escán-

'En 1911, primer premio Penagos por "Firenze"; en 1912 primer premio otra vez Rafael de Penagos por "Tórtola de Valencia"; en 1915, segundo premio Néstor Martín Fernández de la Torre por "Remember"; en 1916, primer premio Penagos por "Japón" y segundo Néstor por "Love»; en 1917, tercer premio Penagos por «Ajenejo»; en 1918, primer premio Ribas por "Fortunato"; en 1919 primer premio para Bartolozzi y accésit para Enrique Ochoa; en 1920, primer premio Ribas y segundo Bartolozzi; en 1923 segundo premio Ramón Manchón y tercero Bartolozzi; en 1928, primer premio Ribas, segundo Penagos y tercero Bartolozzi. 


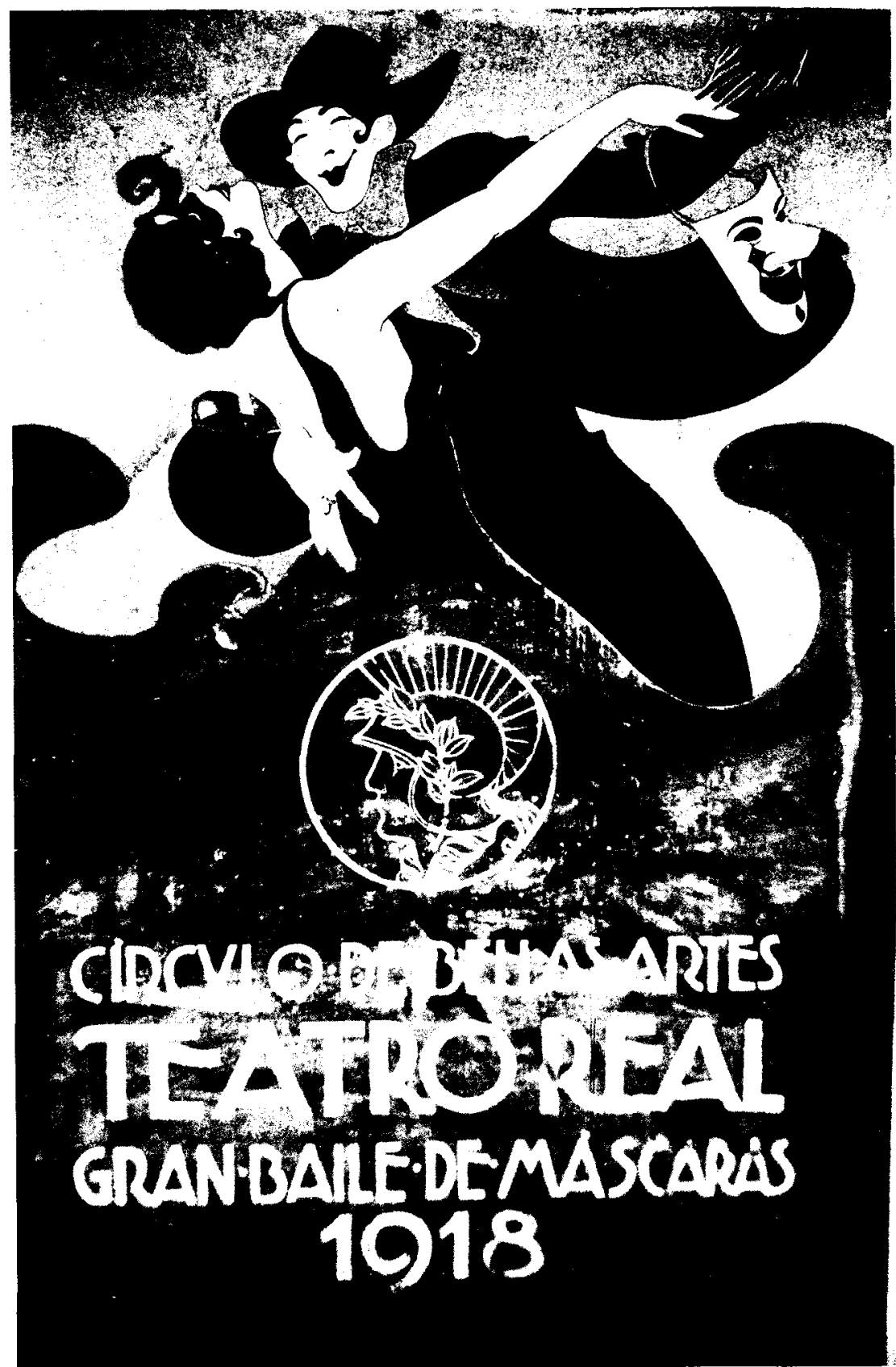

Fig. 7 Ribas, Federico “Fortunato", Circulo de Bellas Artes de Madrid, 1918. 


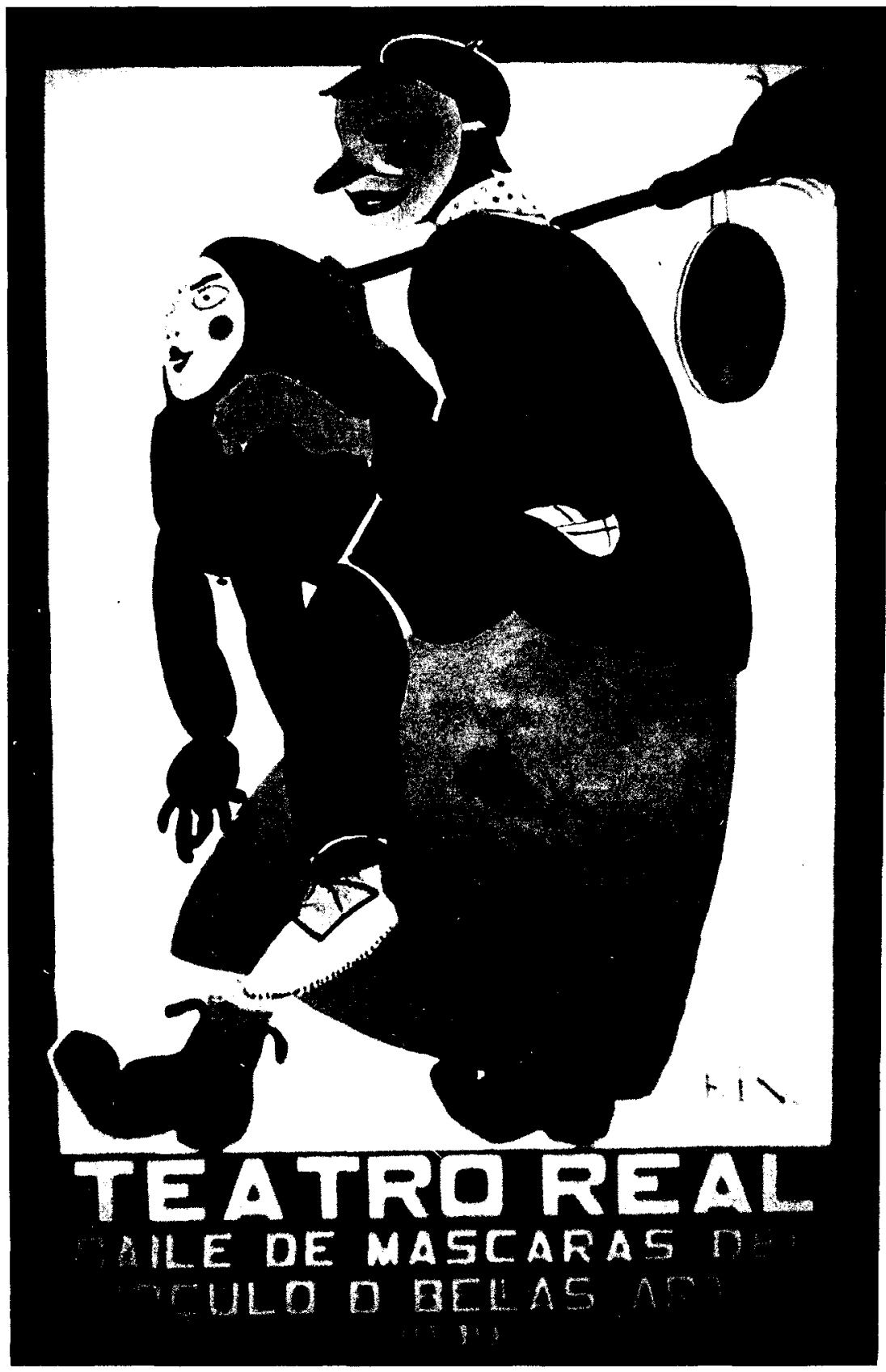

Fig. 8 Bartolozzi, Salvador "La Destrozona", Circulo de Bellas Artes de Madrid, 1919. 


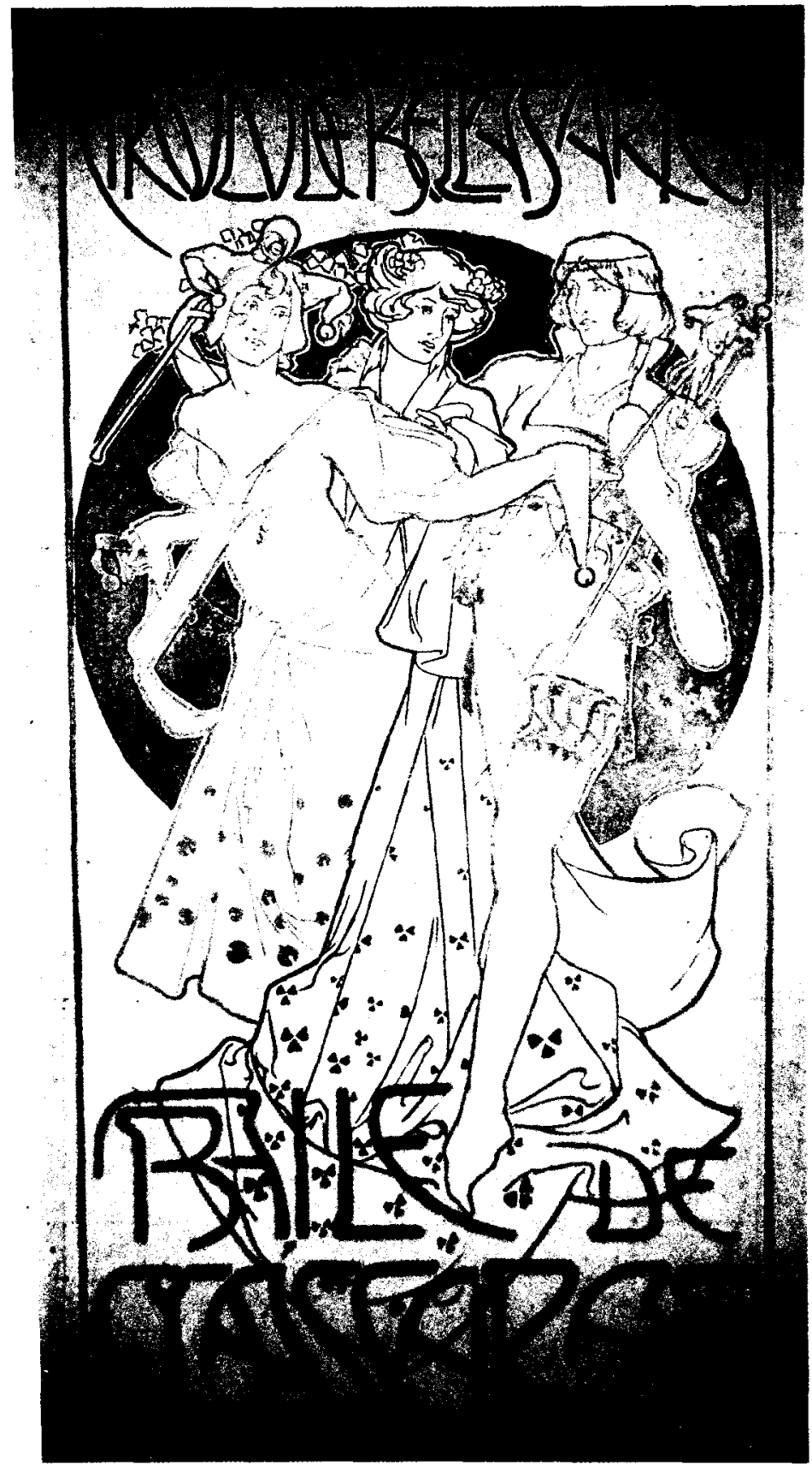

Fig. 9 Vareca y Sartorio, Eulogio "Arte, Juventud y Locura", Circulo de Bellas Artes de Madrid, 1904. 
dalo, el de "La Destrozona" de Salvador Bartolozzi en 1919, que no gustó a muchos de los miembros del Círculo por considerarla vulgar y ofensiva para el emblema de la Institución (colgado de la escoba que lleva el personaje popular) y que no llegó a imprimirse ni a colgarse en las calles.

Carteles y cartelistas para un Madrid que estaba cambiando, que multiplicaba sus habitantes, sus teatros, cines y cafeterías para comenzar a ser una metrópoli moderna, como el mítico Nueva York al otro lado del Atlántico o el tradicional París, la villa de la luz, mucho más cerca. Un Madrid que quizás, a diferencia de Barcelona, no había tenido un movimiento tan definitorio y autóctono como el Modernismo catalán, pero que empezaba el siglo empeñado en recuperar un lengüaje contemporáneo para el que los carteles, colgados en las calles o llamando la atención desde las revistas, parecian ser la forma más moderna. 
